\title{
Habitat preferences and demographic parameters of Nebria brevicollis (Fabricius, 1792) population in an agricultural landscape
}

\section{BRYGIDA RADAWIEC \\ OLEG ALEKSANDROWICZ \\ Pomeranian University in Słupsk \\ Department of Zoology and Animal Physiology \\ Arciszewskiego 22, 76-200 Słupsk, Poland \\ Correspondence: \\ Brygida Radawiec \\ e-mail: brygida.radawiec@apsl.edu.pl}

Keywords: Nebria brevicollis, habitat preferences, agricultural landscape, age structure, sex structure

Received January 15, 2016.

Revised May 31, 2016.

Accepted May 31, 2016

\begin{abstract}
Background and Purpose: Nebria brevicollis is considered a forest species. The aim of this study was to analyze selected aspects of the demographic structure of $\mathrm{N}$. brevicollis in a mosaic of agricultural habitats. We hypothesized that collected demographic parameter vary depending on a habitat (pine forest, cereal crops, old fallow and fresh fallow), and used this differences to identify residential andlor migrant habitats for the species.
\end{abstract}

Materials and Methods: Between 2007 and 2009, the occurrence and habitat preferences of Nebria brevicollis from four types of agricultural landscape habitats (pine forest, old fallow, fresh fallow and cereal crops) in northern Poland were studied. The material was collected by trapping in pitfall traps.

Results: A total of 621 individuals were collected. Activity analysis showed that Nebria brevicollis was present in all four habitat types. However, it was significantly more prevalent in pine forest and old fallow. All developmental stages (teneral, immature, mature and spent) were found in pine forest and old fallow. In fresh fallow and cereal crops, the age structure was disrupted and incomplete. Approximately twice more males than females were recorded in all habitats. The highest average number of eggs per female was recorded in old fallow, and the highest number of eggs produced by a single female in pine forest.

Conclusion: Based on the analyzed features of the Nebria brevicollis sampled populations, this species seems to be a constant element of pine forest and old fallow surface assemblages (preferred habitats), and a migrant element in another two studied habitats (fresh fallow and cereal crops).

\section{INTRODUCTION}

Jebria brevicollis (Fabricius, 1792) is one of the most common been increasingly expanding in North America (3), where its presence has been recorded since 1930. N. brevicollis is generally considered a forest species $(2,4)$. However, multiple studies showed that it can also be frequently encountered in transformed habitats being under a strong anthropogenic influence, such as parks, gardens, hedges, degraded postindustrial areas and fields $(1,3,5)$. Some authors $(6,7,8)$ point to the eurytopic features of $N$. brevicollis and its strong tendencies to disperse and colonize new habitats. La Bonte (3), studied the newly discovered North American populations and showed that some characteristics of 


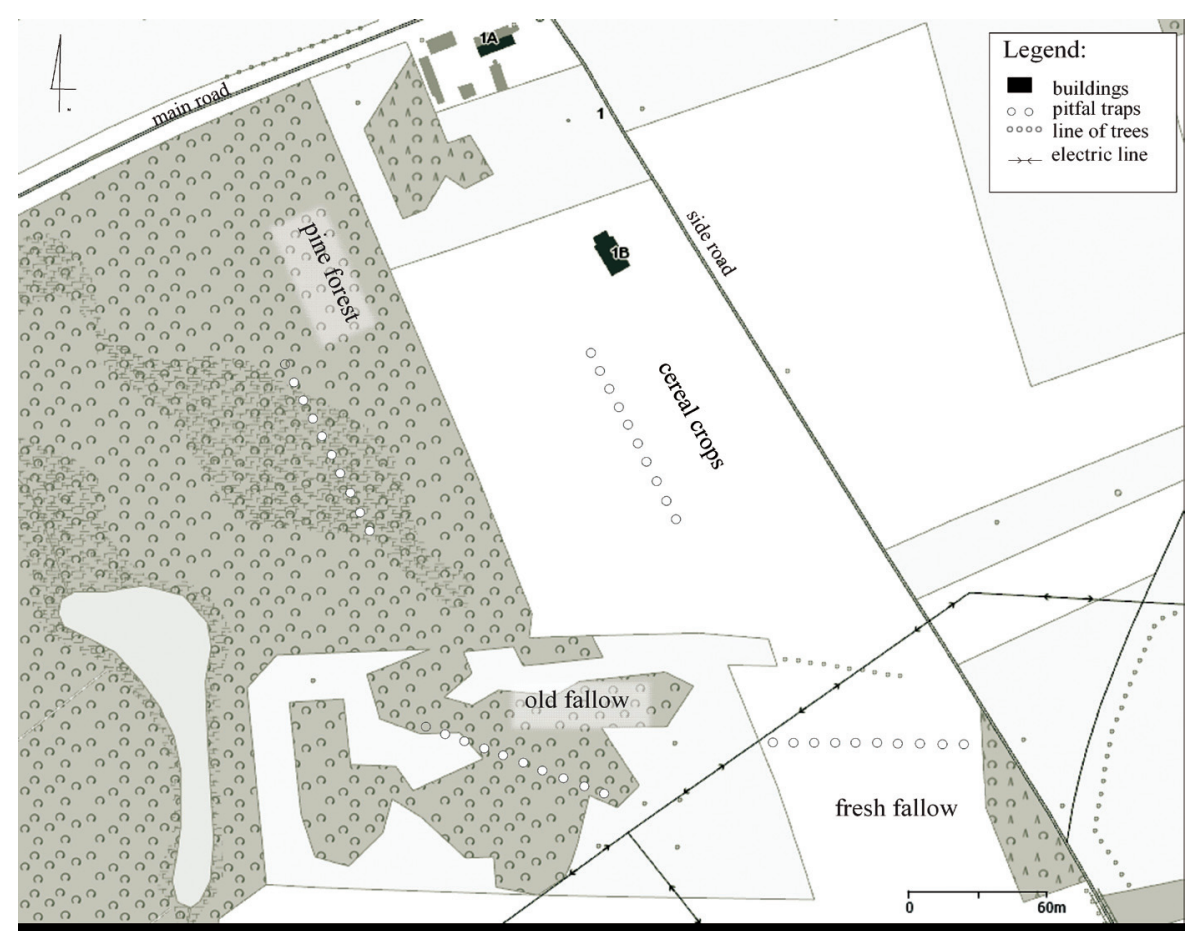

Figure 1. Map showing location of four study habitats in Wiklino village.

$N$. brevicollis biology are specific for an invasive species. According to this author (3), these characteristics include primarily the ability to rapidly and massively colonize new habitats, both anthropogenic and natural ones. Several features of this beetle allow it to thrive in different types of habitats. These include, inter alia: nutrition strategy $(N$. brevicollis are mainly predators and can even hunt on erect herbaceous plants, which differentiates them from other epigeic beetles, but can switch to polyphagism if necessary), and its life-cycle. This species reproduces once in a lifetime (semelparity) and undergoes a characteristic diapause in the most unfavorable time during the vegetative period $(7,9)$. But is a species' occurrence or even occurrence in large numbers enough to conclude that it is resident in the particular habitat? Makarov and Matalin (10) showed that in order to consider a species resident in a given habitat, it has to be characterized by a full demographic structure. Otherwise, we are dealing with migrants or sporadic species. The aim of this study was to analyze selected aspects of the demographic structure of $N$. brevicollis in a mosaic of agricultural habitats to infer which of them can be considered permanent or temporary for this species. We assumed that pine forest is a residential habitat for this beetle and the remaining habitats are migrant (also referred to as sporadic or temporary).

\section{MATERIAL AND METHODS}

The study material was collected between May and October, every year between 2007 and 2009. The study was conducted in four adjacent areas with different types of habitat, in the agricultural landscape of Wiklino village $\left(54^{\circ} 33^{\prime} \mathrm{N}, 17^{\circ} 08^{\prime} \mathrm{E}\right)$ in northern Poland (Table 1, Figure 1). Three areas (all except from the cereal crops) repre-

Table 1. Description of studied areas in agricultural landscape of Wiklino village.

\begin{tabular}{|c|c|c|}
\hline $\begin{array}{l}\text { Habitat's name } \\
\left(\text { area in } \mathrm{m}^{2}\right)\end{array}$ & Subsoil & $\begin{array}{l}\text { Characteristic plant } \\
\text { species }\end{array}$ \\
\hline $\begin{array}{l}\text { Pine forest } \\
\text { (about } 20000 \mathrm{~m}^{2} \text { ) }\end{array}$ & $\begin{array}{l}\text { sandy, penurious, } \\
\text { mosaic, acidic }\end{array}$ & $\begin{array}{l}\text { Pinus sylvestris } \\
\text { Betula pendula } \\
\text { Sambucus nigra } \\
\text { Acer platanoides } \\
\text { Sorbus aucuparia } \\
\text { Agrostis alba }\end{array}$ \\
\hline $\begin{array}{l}\text { Old fallow } \\
\text { (about } 24000 \mathrm{~m}^{2} \text { ) }\end{array}$ & $\begin{array}{l}\text { clay, concise, } \\
\text { impermeable, } \\
\text { mosaic, very acidic }\end{array}$ & $\begin{array}{l}\text { Pinus sylvestris } \\
\text { Betula pendula } \\
\text { Crataegus monogyna } \\
\text { Achillea millefolium } \\
\text { Equisetum arvense } \\
\text { Plantago lanceolata }\end{array}$ \\
\hline $\begin{array}{l}\text { Fresh fallow } \\
\text { (about } 9000 \mathrm{~m}^{2} \text { ) }\end{array}$ & $\begin{array}{l}\text { clay, concise, } \\
\text { uniform, acidic }\end{array}$ & $\begin{array}{l}\text { Rumex acetosa } \\
\text { Lapsana communis } \\
\text { Dactylis glomerata } \\
\text { Taraxacum officinale } \\
\text { Trifolium pratense }\end{array}$ \\
\hline $\begin{array}{l}\text { Cereal crops } \\
\left(\text { about } 22000 \mathrm{~m}^{2} \text { ) }\right.\end{array}$ & $\begin{array}{l}\text { sandy, } \\
\text { homogeneous, } \\
\text { acidic }\end{array}$ & $\begin{array}{l}\text { Triticum aestivum } \\
\text { Aphanes arvensis } \\
\text { Myosotis stricta } \\
\text { Erodium cicutarium } \\
\text { Artemisia vulgaris } \\
\text { Vicia hirsuta }\end{array}$ \\
\hline
\end{tabular}


sented different successive stages of abandoned set aside cereal crops. Pine forest was the oldest succession the age of which exceeded 30 years at the time of the study. This habitat included a fragment of pine forest adjacent to the old fallow (Figure 1). It was characterized by well-developed underbrush and poorly developed cover (Table 1). The old fallow being a subject of the study was an approximately 10 -year-old successive stage after potato and cereal cultivation. This area was characterized by the densest vegetal cover (herbaceous and scrubland) during vegetation period. At the onset of the study, fresh fallow represented a 2-year-old habitat set aside after a cereal culture. It was covered by a low, dense grassland-type vegetal cover (Table 1). Cereal crops were a subject of continuous cultivation. Following cultivation of potatoes in 2004, it was used for cultivation of cereal mixture (spring barley, spring wheat, oats) alternately with spring wheat and winter wheat. The land was a subject to routine agrotechnical procedures, such as fertilizing, chemical defoliation and ploughing. Every year, in the $1^{\text {st }}$ and $3^{\text {rd }}$ decade of May, the soil was conditioned with urea, following treatment with phosphate-potassium fertilizers in autumn. Chemical defoliation with Roundup was performed once a year, in the $3^{\text {rd }}$ decade of July, and ploughing in early October.

Material for analyses was collected to setting pitfall traps, i.e. plastic cups with 0.5 -liter volume and $10-\mathrm{cm}$ diameter, set up in approximately $10-\mathrm{m}$ intervals in rows located in the central part of each land, i.e. apart from the ecotone (Figure 1). We installed 10 traps filled with $5 \mathrm{~cm}^{3}$ of ethylene glycol-in-water solution in all areas. Location of the traps was the same during each year of the study. The traps were emptied every 12-14 days. Collected specimens, after cleaning and drying, were stored in cotton wool in paper envelopes. We immersed the insects in hot water bath with acetic acid for about $20 \mathrm{~min}$ to soften and loosen their chitin cuticle. During preparation, we assessed condition of the mandibles, reproductive organs, gonads, presence or lack of eggs and size of the fat body. Aside from establishing beetle's sex, we used these characteristics to classify each specimen into one out of four the age- and physiology-based categories (teneral, immature, mature or spent) proposed by Wallin (11). Individuals with sharp mandibles, brighter elytra, without gonads and fat bodies were classified at tenerals. According to Matalin's typology (9), N. brevicollis tenerals are active in May and June. Individuals with sharp mandibles, hard, dark tegument and early developmental stages of gonads (small non-transparent ovaries and testicles) were classified as immature. Immature females lacked eggs and similar to males presented with well-developed fat body. Characteristic features of mature individuals included presence of blunt mandibles and fully developed gonads. Females had eggs, and fat body was considerably reduced in both sexes. Immature and mature individuals are active during the second half of reproductive cycle, between
August and October (9). Specimens with apparently reduced mandibles, smaller gonads and atrophic fat bodies were classified as spent. No eggs were found in spent females. Specimens from this category are typically found in late October (9).

Statistical analysis was performed according to Stanisz (12), using STATISTICA Statistical Software Package v8.0 (StatSoft Inc.). We used one-way analysis of variance (ANOVA) to compare mean number of individuals collected during consecutive years in various habitats, as well as a mean number of eggs per female. Mean number of eggs was calculated per a total number of females collected from various habitats throughout three years of the study. Normal distribution and homogeneity of variance were checked using Shapiro-Wilk's and Levene's tests. In order to establish which mean values affected the ANOVA results, we used Tukey's post-hoc test. We used $\chi^{2}$ tests to compare the distribution of specimens based on age category and sex. These analyses did not include fresh fallow data, due to insufficient number of beetles in this habitat ( $<10$ individuals), which made this land ineligible for $\chi^{2}$ testing. Mean values are presented with their standard errors (SE).

\section{RESULTS}

During the course of the study we have collected a total of 621 Nebria brevicollis specimens. Mean number of collected individuals amounted to $\bar{X}=0.38 \pm 0.68$ SE per trap per day, and was demonstrated to increase slightly between 2007 and 2009 (Figure 2a). However, the yearto-year differences in mean number of collected individuals turned out to be insignificant on statistical analysis (ANOVA F $=0.098 ; p>0.5$ ). However, statistically significant differences were found in the number of individuals collected from various habitats. The highest number of individuals were collected from old fallow ( $\overline{\mathrm{X}}=0.68 \pm 0.11 \mathrm{SE}$ ) and pine forest $(\overline{\mathrm{X}}=0.60 \pm 0.21 \mathrm{SE})$, and the lowest from fresh fallow ( $\overline{\mathrm{X}}=0.03 \pm 0.01 \mathrm{SE}$ ) (Figure $2 \mathrm{~b}$ ). Mean numbers of individuals caught in old fallow and pine forest were significantly higher than in the case of fresh fallow and cereal crops $(F=5.901 ; p<0.001$, Tukey's test: pine forest vs. old fallow $p>0.05$, pine forest vs. fresh fallow $p<0.05$, pine forest vs. cereal crops $p>0.05$, old fallow vs. fresh fallow $\mathrm{p}<0.05$, old fallow vs. cereal crops $\mathrm{p}<0.05$ ).

All areas aside from fresh fallow were dominated by physiologically older specimens from the second stage of the life cycle, i.e. immature, mature and spent individuals. Altogether, mature and spent individuals represented $67 \%$ of all collected specimens. While mature ( $\mathrm{N}=98$ for pine forest and $\mathrm{N}=34$ for cereal crops) and immature individuals ( $\mathrm{N}=109$ on old fallow) turned out to be the most frequently caught specimens (Table 2, Figure $3 \mathrm{a}-\mathrm{c}$ ), tenerals were collected least often of all analyzed categories ( $\mathrm{N}=12$ for old fallow and $\mathrm{N}=2$ for cereal crops) (Table 2, Figure 3a-c). Significant differences were found in the 

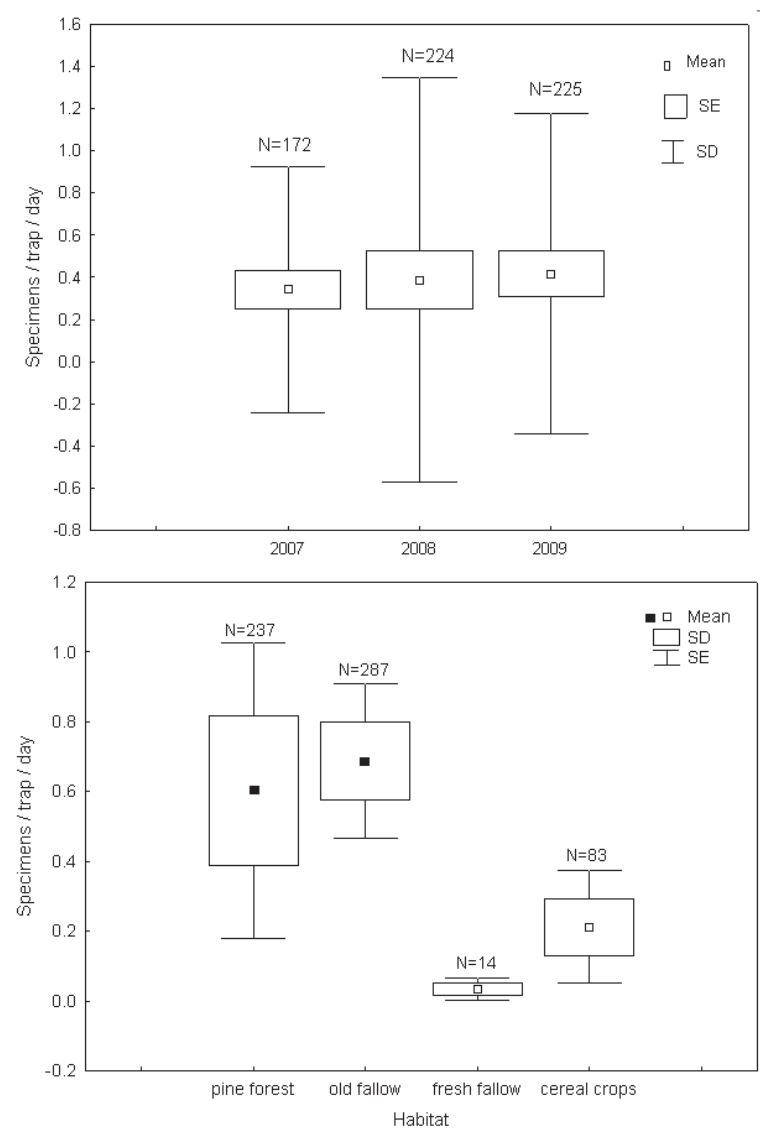

Figure 2. Number of Nebria brevicollis specimens collected during subsequent years of the study (a) and mean number of specimens collected from each analyzed habitat during the course of the study (b). (- stands for statistically significant differences).

distribution of immature, mature and spent specimens within various habitats $\left(\chi^{2}=19.843, \mathrm{df}=4, \mathrm{p}<0.05\right)$. Statistical analysis did not include data for fresh fallow, since no tenerals and spent individuals were collected from this area.

An evident decrease in the number of specimens collected in mid vegetative season was documented during the course of the study. No specimens were found in traps set in pine forest in July and August (Figure 3). In the case of cereal crops, the lowest activity of the analyzed species was observed in July, and in the case of old fallow in July and September (Figure 3).

Irrespective of the habitat, males outnumbered females approximately twice. The largest and the smallest proportions of males were observed in cereal crops and old fallow, respectively (Table 2). However, proportions of male and female specimens in various habitats (except from fresh fallow) did not differ significantly $\left(\chi^{2}=2.669\right.$, $\mathrm{p}>0.05)$. Proportions of males and females within particular developmental stages (excluding tenerals, as the smallest group) from various habitats (excluding fresh fallow) turned out to be similar for pine forest $\left(\chi^{2}=2.057\right.$,

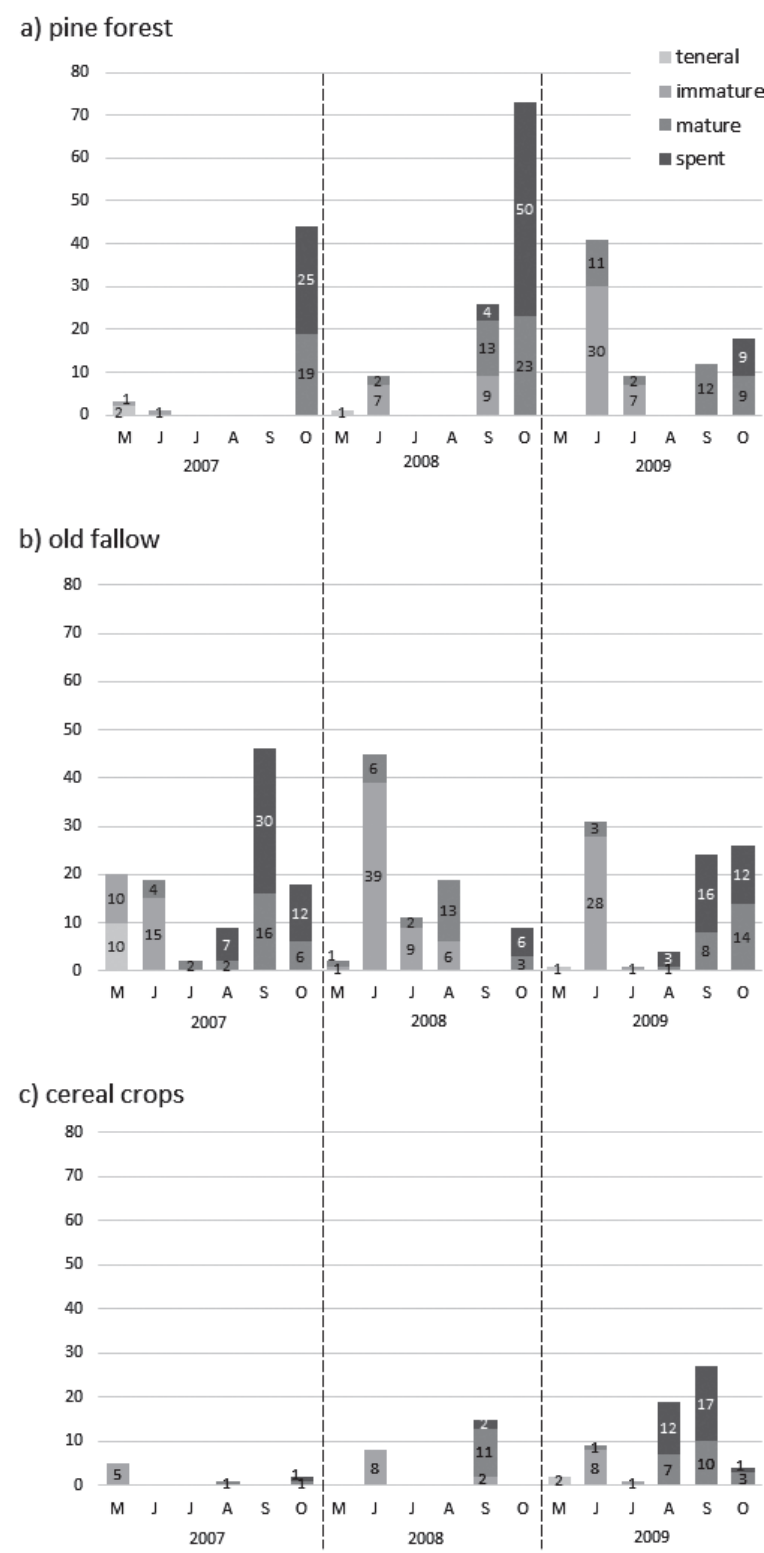

Figure 3. Number of individuals representing various physiological stages of Nebria brevicollis caught in vegetative season during subsequent years of the study (data for fresh fallow were excluded from the analysis due to a small number of collected specimens).

$\mathrm{p}>0.05)$ and cereal crops $\left(\chi^{2}=0.050, \mathrm{p}>0.05\right)$, but was significantly different in the case of old fallow $\left(\chi^{2}=7.374\right.$, $\mathrm{p}<0.05$ ) (Figure $4 \mathrm{a}-\mathrm{d}$ ).

We captured the largest proportion of females (over $50 \%$ ) in old fallow (Figure 5). The largest proportion of mature females with eggs was recorded on pine forest. Mean number of eggs per female (calculated for all collected females) turned out to be the highest in pine forest, $6.73 \pm 0.95 \mathrm{SE}$ (Figure 5). This value differed significantly as compared to other habitats (ANOVA F $=4.248, \mathrm{p}<0.05$, Tukey's test: pine forest vs. old fallow $\mathrm{p}<0.05$, pine forest 


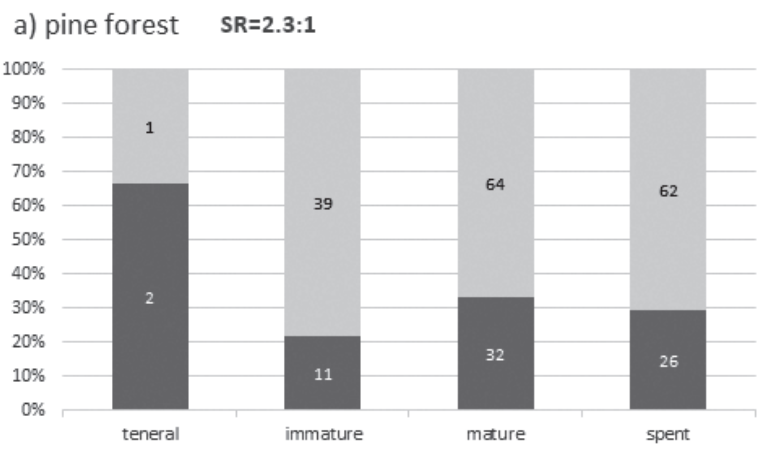

\section{b) old fallow $\quad S R=1.9: 1$}

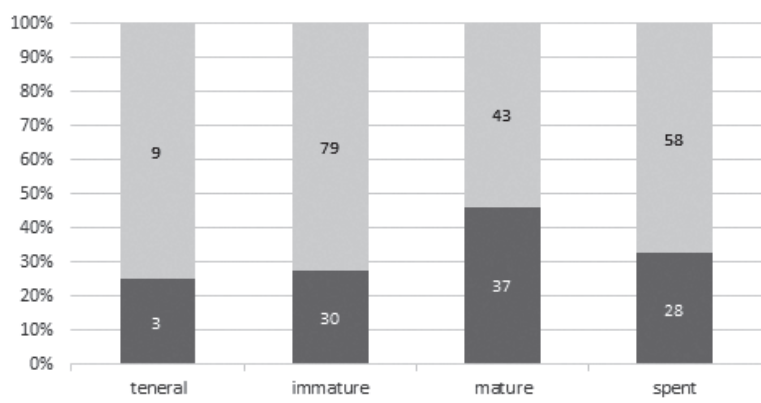

d) cereal crops $\quad$ SR=2.9:1

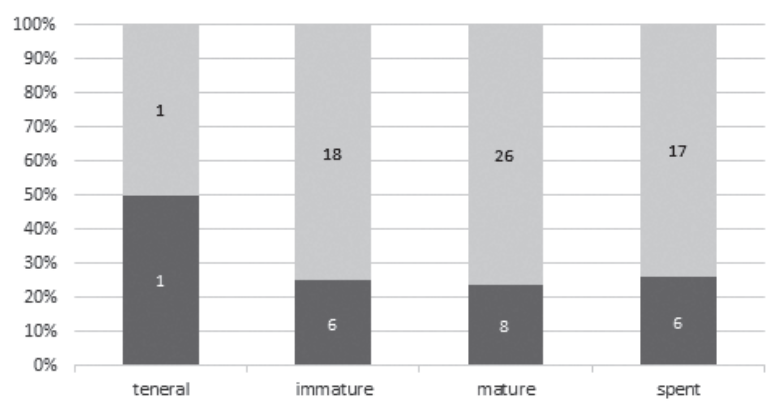

Figure 4. Proportions of male and female Nebria brevicollis within particular developmental stages from analyzed habitats. All data for 20072009. SR - sex-ratio (males:females).

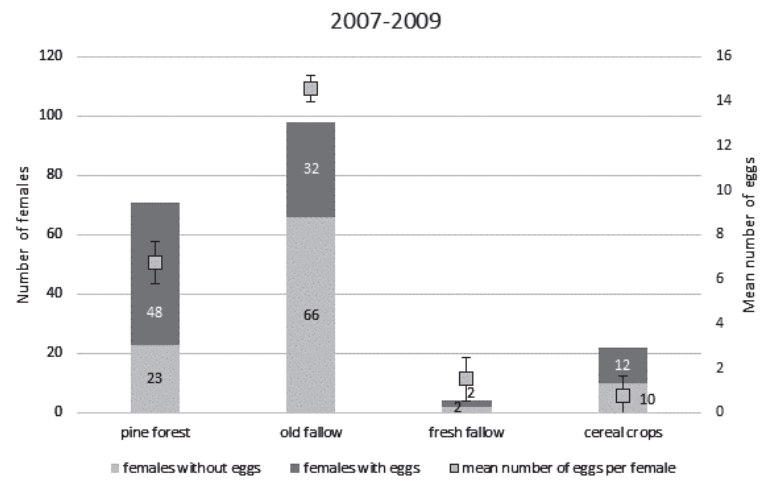

Figure 5. Number of females with and without eggs in each habitat and mean number of eggs per female \pm SE. All data for 2007-2009.

vs. cereal crops $\mathrm{p}>0.05$, old fallow vs. cereal crops $\mathrm{p}>0.05$ ). In pine forest, we captured three females with 40 eggs, which constituted the largest recorded amount of eggs.

\section{DISCUSSION}

We found $N$. brevicollis in all four types of habitats. This is not surprising since we included pine forest in the analyzed landscape mosaic. La Bonte (3), Garcia et al. (1) and Fahy and Gormally (13) stressed the significance of forest habitats for the occurrence of this species in various types of habitats adjacent to the forest. They pointed that forests constitute the estivation spot for $N$. brevicollis, from which they may disperse to adjacent habitats in landscape without barriers (e.g. canals, rivers).

Year-to-year variation in mean number of caught individuals was small (Figure 2a). Small differences in the activity of the analyzed species in different vegetable crops were also documented by Eyre et al. (14) and Günther and Assmann (8) who conducted a 10-year study in oak and beech forests in northern Germany. According to Günther and Assmann (8), interannual changes in the number of $N$. brevicollis never surpassed one order of magnitude, in

Table 2. Selected features of $\mathrm{N}$. brevicollis populations from the analyzed areas, pooled data for 2007-2009.

\begin{tabular}{|c|c|c|c|c|c|}
\hline Habitat & Specimen/trap/day & Completeness of age structure & Estivation period & $\begin{array}{c}\text { Sex ratio } \\
\text { (males:females) }\end{array}$ & $\begin{array}{l}\text { Mean number of } \\
\text { eggs per female }\end{array}$ \\
\hline Pine forest & $0.60 \pm 0.21 S E$ & complete & July and/or August & $2.3: 1$ & $6.73 \pm 0.95$ \\
\hline Old fallow & $0.68 \pm 0.11 \mathrm{SE}$ & complete & July and/or September & 1.9:1 & $3.26 \pm 0.60$ \\
\hline Fresh fallow & $0.03 \pm 0.01 S E$ & $\begin{array}{l}\text { incomplete (lack of specimen } \\
\text { in teneral and spent stages) }\end{array}$ & $\begin{array}{l}\text { impossible to determine (too } \\
\text { small numbers of specimen) }\end{array}$ & $2.5: 1$ & $1.50 \pm 0.96$ \\
\hline Cereal crops & $0.21 \pm 0.08 \mathrm{SE}$ & $\begin{array}{l}\text { complete (low number of } \\
\text { specimen in teneral stage) }\end{array}$ & July and/or August & 2.9:1 & $3.36 \pm 0.89$ \\
\hline
\end{tabular}


contrast to other beetle species, e.g. Pterostichus niger. Many previous studies documented variability in the activity of the species from different habitats $(1,14,15,16)$. Aside from the type of soil and flora, also the height of the vegetation is with no doubt one of the significant differentiating factors. Eyre et al. (14) showed a positive correlation between the activity of $N$. brevicollis and vegetation height. Our observations are consistent with this finding. Fresh fallow with a very low, grassy vegetation, was characterized by the lowest number of caught individuals, one order of magnitude lower than in other habitats (Figure 2b.). Similarly, low activity of the species in cereal crops has been also previously reported by Huruk (15) and Huruk (16) for various types of cereal cultures. Extremely dense population of $N$. brevicollis in cereal cultures from northern Poland was documented in a one-year study conducted by Aleksandrowicz et al. (17), who classified this species as a dominant category. However, authors of this latter study did not analyze the population's structure, and consequently, despite its high activity, $N$. brevicollis might have been a migrant in the analyzed habitat.

La Bonte (3) and Makarov and Matalin (10) emphasized the fact that several species of carabidae, including $N$. brevicollis can occur in large numbers although they do not constitute a stable element of the assemblage. According to Makarov and Matalin (10), the key to qualify the species as a stable element of an assemblage in a given habitat is determination of its complete demographic structure. In present study, populations from four analyzed habitats differed in terms of their age and sex structures. Matalin (9) classified N. brevicollis as a semelparous beetle with autumnal, annual type of development. Tenerals of semelparous species can be found in spring, in the second half of May and first half of June. This is a period of great activity for the new generation of adults, during which they prey extensively, to gather as much fat reserves as possible $(18,9)$. In our present study, irrespective of the habitat, tenerals were collected least frequently from all the analyzed developmental stages (Figure 3 and 4). This fact can be linked to the ability of the species to climb plants and prey on them, as described by La Bonte (3) and Burgess et al. (7). Lower activity of tenerals on the ground was reflected by lower number of caught individuals. According to Matalin (9), the period between the second half of June through July and August, is a time of estivation, i.e. a significant decrease in the activity of adults. In our geographical latitude, the diapause of the species takes place during the warmer period of the year, when water and food are scarce. The period following estivation, i.e. the second part of August through October, is a time of high activity for immature and mature adults (9). These two developmental stages tied with the reproduction of the species. Activity during this period is more connected with the ground, and as a result, the number of caught adults is greater than the number of tenerals.
The number of caught post-estivation specimens (immature, mature, spent) turned out to be the highest in old fallow and pine forest (Figure 3). In these two habitats we observed complete demographic structure of the species, which corresponds to its stable occurrence in these habitats. Demographic structure of the analyzed species was in turn most disrupted in fresh fallow, whereby neither tenerals nor spent individuals were caught. According to Makarov and Matalin (10), this points to evident migratory character of the species within a given habitat.

Proportion of males and females within a population is determined by a number of factors, including environment, life strategy, age structure and availability of food (19). The male to female ratio directly affects the growth of the population. From the viewpoint of potential offspring, the most favorable male to female ratio for monogamous species is 1:1. In polygamous species, in turn, reproductive potential is greater if males are outnumbered by females (19). Our hereby presented findings imply that preferable reproductive strategy of $N$. brevicollis is not based only on the number of females, but also on their fertility, expressed as the number of produced eggs. Based on their laboratory study, Burgess et al. (7) concluded that females of $N$. brevicollis are significantly heavier than males for up to 13 days after estivation. Probably, this results from accumulation of energy reserves, which are then utilized to produce large amount of eggs and thus to promote development of the species. Although mean number of eggs per female documented in this study $(6.73 \pm 0.95$ SE for pine forest, Figure 5) does not seem large, the fact that 30 or 40 eggs were found in some females from this area points to likely large reproductive potential of $N$. brevicollis. In other epigeic ground beetles, mean number of eggs per female is significantly lower. According to Wallin (11), this parameter does not exceed 26 for Pterostichus cupreus and 16 for Harpalus rufipes.

The hereby documented differences in the male to female ratio in various habitats point to area-specific sex structure of the populations. Evidently, the most favorable structure was documented in old fallow, and the most disrupted in cereal crops (Figure 4).

The fact that males outnumbered females is difficult to explain and requires further research. Based on the hereby documented structure of $N$. brevicollis population from four habitats (Table 2) and previous observations by Makarov and Matalin (10), it can be concluded that the species represents a stable element of pine forest and old fallow assemblages, and should be considered a partially migratory component in the case of the two remaining areas.

In our opinion, the presence of resident populations of $N$. brevicollis on old fallow is a sign of succession of this habitat. 


\section{REFERENCES}

1. GARCÍA A F, GRIFFITHS G J K, THOMAS C F G 2000 Density, distribution and dispersal of the carabid beetle Nebria brevicollis in two adjacent cereal fields. Ann Appl Biol 137: 1-9 http://dx.doi.org/10.1111/j.1744-7348.2000.tb00040.x

2. LUFF L M 2007 The Carabidae (ground beetles) of Britain and Ireland. Royal Entomological Society. Newcastle: 48-49

3. LA BONTE RJ 2011 Nebria brevicollis (Fabricius, 1792) in North America, benign or malign? (Coleoptera, Carabidae, Nebriini). ZooKeys 147: 497-543

4. GREENSLADE P J M 1964 The distribution, dispersal and size of a population of Nebria brevicollis (F.), with comparative studies on three other Carabidae. J Anim Ecol 33: 311-333 http://dx.doi.org/10.2307/2633

5. KOPP A 1997 Field margins as overwintering habitat and effects of beneficial arthropods on cereal aphids. In: Field Boundary Habitats for Wildlife, Crop and Environmental Protection. Final Report: 188-196. Ed. E J P Marshall. Bristol

6. DEN BOER P J 1990 Density limits and survival of local populations in 64 carabid species with different powers of dispersal. J Evol Biol 3: 19-48 http://dx.doi.org/10.1046/j.1420-9101.1990.3010019.x

7. BURGESS E P J, LÖVEI G L, MALONE L A, NIELSEN I W, GATEHOUSE H S, CHRISTELLER J T 2002 Prey-mediated effects of the protease inhibitor aprotinin on the predatory carabid beetle Nebria brevicollis. J Insect Physiol 48: 1093-1101 http://dx.doi.org/10.1016/S0022-1910(02)00202-0

8. GÜNTHER J, ASSMANN T 2004 Fluctuations of carabid populations inhabiting an ancient woodland (Coleoptera, Carabidae). Pedobiologia 48: 159-164 http://dx.doi.org/10.1016/j.pedobi.2003.11.002

9. MATALIN A V 2007 Typology of Life Cycles of Ground Beetles (Coleoptera, Carabidae) in Western Palaearctic. Entomological Review 8: 947-972

http://dx.doi.org/10.1134/S0013873807080027
10. MAKAROV K V, MATALIN A V 2009 Ground-beetle communities in the Lake Elton region, southern Russia: a case study of a local fauna (Coleoptera: Carabidae). In: Species and Communities in Extreme Environments. Golovatch S I, Makarova O L, Babenko A B, Penev L D (Eds), p 357-384

11. WALLIN H 1989 The influence of different age classes on the seasonal activity and reproduction of four medium-sized carabid species inhabiting cereal fields. Holarct Ecol 12: 201-212 http://dx.doi.org/10.1111/j.1600-0587.1989.tb00839.x

12. STANISZ A 1998 Przystępny kurs statystyki w oparciu o program STATISTICA PL na przykładach z medycyny. StatSoft Polska. Kraków

13. FAHY O, GORMALLYM 1998 A comparison of plant and carabid beetle communities in an Irish oak woodland with a nearby conifer plantation and clearfelled site. For Ecol Manage 110: 263-273

14. EYRE M D, LABANOWSKA-BURY D, AVAYANOS J G, WHITE R, LEIFERT C 2009 Ground beetles (Coleoptera, Carabidae) in an intensively managed vegetable crop landscape in eastern England. Agriculture, Ecosystems and Environment 131: 340-346

15. HURUK S 2006 Comparison of structure of carabid (Coleoptera: Carabidae) communities of hay meadows and adjacent cultivated fields. Wiadomości Entomologiczne 25: 9-32

16. HURUK A 2014 Zgrupowania biegaczowatych (Coleoptera, Carabidae) dużych pól uprawnych. Wydawnictwo Uniwersytetu Jana Kochanowskiego Kielce

17. ALEKSANDROWICZ O P, RADAWIEC B, WIECZORKIEWICZ K 2015 Zhuzhelitsy (Coleoptera, Carabidae) na pole ozimoi pshchenitsy v Zapadnopomorskom voevodstve. Zoologichni doslidzhennya. In: 1st International extramural scientific-practical Conference "Current issues of biological science" Nizhyn State Gogol University, Ukraine, p 125-142

18. PENNEY M M 1969 Diapause and reproduction in Nebria brevicollis (F.) (Coleoptera: Carabidae). J Anim Ecol 38: 219-233. http://dx.doi.org/10.2307/2748

19. BEGON M, MORTIMER M, THOMPSON D J 1999 Ekologia populacji. Studium porównawcze roślin i zwierząt. PWN Warszawa 
